\title{
AÇÕES EXTENSIONISTAS DA ÁREA DE SAÚDE DE UMA UNIVERSIDADE PÚBLICA BRASILEIRA
}

\section{ARTIGO ORIGINAL}

PEREIRA, Ellan Peixoto ${ }^{1}$, SANTOS, Thallyta dos $^{2}$, SAMPAIO, Josineide Francisco ${ }^{3}$

PEREIRA, Ellan Peixoto. SANTOS, Thallyta dos. SAMPAIO, Josineide Francisco. Ações extensionistas da área de saúde de uma universidade pública brasileira. Revista Científica Multidisciplinar Núcleo do Conhecimento. Ano 06, Ed. 07, Vol. 01, pp. 36-53. Junho de 2021. ISSN: 2448-0959, Link de acesso: https://www.nucleodoconhecimento.com.br/saude/acoes-extensionistas, $\quad$ DOI: 10.32749/nucleodoconhecimento.com.br/saude/acoes-extensionistas

\section{RESUMO}

A Extensão Universitária consiste em um processo educativo, científico e cultural que articula a Pesquisa e o Ensino de forma indissociável e viabiliza uma relação transformadora entre Universidade e Sociedade. Trata-se de um processo acadêmico que deve ter suas ações pautadas em diretrizes estabelecidas pela Política Nacional de Extensão (PNE), sendo fundamental para a formação do estudante e para o estabelecimento de intercâmbio com a sociedade. O presente estudo tem como objetivo apresentar o resultado de uma pesquisa de análise documental das propostas de Projetos de Extensão cadastradas na plataforma digital SIGAA/PROEX dos cursos de Enfermagem, Medicina, Nutrição e Odontologia da Universidade Federal de Alagoas (UFAL) no período de 2018 e 2019; sendo feita uma análise descritiva das propostas, seguida de uma análise da consonância das

\footnotetext{
${ }^{1}$ Graduação em Farmácia pela UNIPAC - Universidade Presidente Antônio Carlos (2011). Acadêmico do $10^{\circ}$ período do Curso de Medicina da UFAL - Universidade Federal de Alagoas/Campus Maceió/AL.

${ }^{2}$ Graduanda em Medicina.

${ }^{3}$ Orientadora. Doutorado em Ciências da Saúde/Saúde Pública pela Escola Nacional de Saúde Pública Sérgio Arouca - ENSP/FIOCRUZ.
}

RC: 90188

Disponível em: https://www.nucleodoconhecimento.com.br/saude/acoes- 
mesmas com as diretrizes da Política Nacional de Extensão (PNE). Verificou-se que as atividades educativas foram as principais ações desenvolvidas pelos projetos. Como se trata do processo de formação dos profissionais da área da saúde na universidade, foi possível perceber que a aplicação da interdisciplinaridade ainda carece de aperfeiçoamento para tornar o processo de ensino e aprendizagem mais efetivo. Nota-se que há uma necessidade de maior inserção das atividades extensionistas no ambiente das comunidades, fora da universidade; e, aliado a isso, percebe-se que há um déficit no enquadramento e prática de algumas diretrizes preconizadas pela PNE, em destaque a diretriz de Interação Dialógica, pouco compreendida e incorporada nas propostas. Conclui-se que se faz necessária ainda a criação de novas estratégias que permitam uma articulação entre a universidade e comunidade de forma mais eficiente a fim de que a Extensão Universitária seja integralizada nas universidades brasileiras como ferramenta capaz de proporcionar uma troca de saberes entre universidade e comunidade.

Palavras-chave: Extensão Comunitária, Extensão Universitária, Formação em Saúde.

\section{INTRODUÇÃO}

A Extensão Universitária se faz presente no contexto brasileiro desde o início do século XX até os dias de hoje, tratando-se de um processo acadêmico fundamental para a formação do estudante e para o estabelecimento de intercâmbio com a sociedade, que deve ter suas ações formuladas e implementadas pautadas em diretrizes estabelecidas pela Política Nacional de Extensão Universitária (PNE), tendo em vista as exigências da realidade (DE PAULA, 2013).

A prática da Extensão tem origem na concepção de universidade detentora do saber que deveria, por um lado, ser compartilhado com a população e, por outro, ser colocado para assistir à população com o provimento de algum serviço (ALMEIDA, 2010; PAULA, 2013). Nesse sentido, a Extensão Universitária apresenta papel

RC: 90188

Disponível em: https://www.nucleodoconhecimento.com.br/saude/acoes- 
preponderante nas universidades públicas brasileiras reforçando a necessidade da extensão integrante de um processo educativo, científico e cultural que articula o ensino e a pesquisa, de forma indissociável, viabilizando a relação transformadora entre universidade e sociedade (FORPROEX, 2012).

O Ministério da Educação (ME) através da Resolução nำ7, de 18 de dezembro de 2018, apresenta a concepção da extensão universitária da seguinte forma:

A Extensão na Educação Superior Brasileira é a atividade que se integra à matriz curricular e à organização da pesquisa, constituindose em processo interdisciplinar, político educacional, cultural, científico, tecnológico, que promove a interação transformadora entre as instituições de ensino superior e os outros setores da sociedade, por meio da produção e da aplicação do conhecimento, em articulação permanente com o ensino e a pesquisa (BRASIL, 2018, Art. $\left.3^{\circ}\right)$.

Uma maneira de inserir as atividades extensionistas de forma regular na graduação é através dos projetos pedagógicos dos cursos superiores; pode-se dizer que o projeto pedagógico deverá buscar a formação integral e adequada do estudante por meio da articulação entre ensino, pesquisa e extensão (BRASIL, 2014). Nesse contexto, merece destaque o fato de que, na Lei $\mathrm{n}$ 13.005, de 25 de junho de 2014, a qual aprova o Plano Nacional de Educação (PNE), consta a determinação de que, no mínimo, $10 \%$ do total de créditos curriculares exigidos para a graduação sejam referentes a programas e projetos de extensão universitária, sendo suas ações orientadas, prioritariamente, para áreas de grande pertinência social (BRASIL, 2014).

Diante deste cenário, o Conselho Universitário da Universidade Federal de Alagoas (CONSUNI/UFAL), frente às disposições do PNE, aprovou em 2014, a Resolução n-65/2014, de 03 de novembro de 2014, a qual estabelece a atualização das diretrizes gerais das atividades de extensão no âmbito da Universidade Federal de Alagoas (UFAL). Consta em tal resolução que as atividades de extensão na UFAL se darão a partir das diretrizes preconizadas pela PNE, sendo elas: a) Interação

RC: 90188

Disponível em: https://www.nucleodoconhecimento.com.br/saude/acoes- 
Dialógica, na qual se orienta o diálogo e a troca de saberes entre a Universidade e a Sociedade como instrumentos que contribuam para a formação do saber, de forma que tanto os estudantes quanto a comunidade passam a ser atores sociais envolvidos na produção de conhecimentos; b) Interdisciplinaridade e Interprofissionalidade, onde se considera a complexidade de estrutura e funcionamento inerentes às comunidades e busca-se a articulação da especialização e da visão holística para que as ações de extensão se tornem de fato efetivas; c) Indissociabilidade Ensino-Pesquisa-Extensão, na qual se assume que a Extensão Universitária torna-se mais efetiva quando associada aos processos de formação de indivíduos e produção de conhecimentos, e nesse contexto o estudante assume o protagonismo de sua formação técnica e cidadã, não se limitando mais ao conceito de "sala de aula" como o espaço físico tradicional de ensino-aprendizagem; d) Impacto na Formação do Estudante, onde se possibilita o engrandecimento teórico e metodológico da experiência discente através da ampliação do universo de referência no qual os estudantes estão inseridos bem como a reflexão e ação acerca das questões contemporâneas despertadas; e, por fim, e) Impacto e Transformação social, diretriz esta que espera imprimir, nas ações extensionistas, as características de consideração da complexidade da realidade social com privilegiamento dos quesitos sobre os quais atuar, abrangência das ações de forma a oferecer contribuição relevante sobre o setor abordado da sociedade e efetividade na solução do problema, promovendo assim a transformação não só na sociedade, mas também na própria Universidade (FORPROEX, 2012).

Sendo assim, as universidades - de acordo com a legislação brasileira - devem estar fundamentadas sobre o tripé formado: ensino, pesquisa e extensão, conforme preconiza o artigo 207 da Constituição Brasileira (BRASIL, 1988; CAVALCANTE et al., 2018). Portanto, tem-se, atualmente, no que diz respeito a formação de profissionais das Ciências da Saúde, a necessidade de um ensino colaborativo, envolvido por docentes, discentes, usuários, gestores, profissionais da saúde e comunidade, que proporcione uma educação voltada para além da transmissão dos

RC: 90188

Disponível em: https://www.nucleodoconhecimento.com.br/saude/acoes- 
conhecimentos, baseada na problematização e transformação da realidade (CARVALHO, 2019).

\section{OBJETIVOS}

Apresentar o resultado de uma pesquisa de análise documental das propostas de projetos de extensão cadastrados no Sistema Integrado de Gestão de Atividades Acadêmicas (SIGAA) dos cursos de Enfermagem, Medicina, Nutrição e Odontologia, da Universidade Federal de Alagoas (UFAL).

\section{METODOLOGIA}

Este estudo classifica-se como uma pesquisa de caráter exploratório e descritivo, com abordagem qualitativa, desenvolvido na Universidade Federal de Alagoas (UFAL) - Campus A. C. Simões em Maceió/AL e realizado por meio de procedimentos de análise documental, tendo como universo de pesquisa os Projetos de Extensão cadastrados pelos cursos de Enfermagem, Medicina, Nutrição e Odontologia da UFAL.

Foram analisadas as propostas de projetos de extensão cadastradas na plataforma digital SIGAA/PROEX da UFAL, que foram executados no período de 2018 e 2019. Nesta análise, foi realizada a leitura e sistematização das propostas, onde foram observadas as características de: período de execução, público-alvo atingido, ações a serem desenvolvidas, área de conhecimento, natureza, cursos envolvidos, local de execução e a presença das diretrizes da PNE. Estas características foram organizadas e armazenadas em plataforma digital, e em seguida foi realizada a análise de tais propostas com auxílio da construção de elementos gráficos como quadros e gráficos a fim de se avaliar a adequação dos projetos de extensão com as diretrizes da PNE.

RC: 90188

Disponível em: https://www.nucleodoconhecimento.com.br/saude/acoes- 
Esta pesquisa foi iniciada após submissão e aprovação do Projeto de Pesquisa intitulado: "Projetos de extensão e ligas acadêmicas e a formação de estudantes da área de saúde da Universidade Federal de Alagoas" no Programa Institucional de Bolsas de Iniciação Científica (PIBIC) em vigência do Edital PIBIC 2019/2020 da UFAL, o qual também foi aprovado pelo Comitê de Ética em Pesquisa (CEP) sob o número de parecer 4.113.506. Os resultados apresentados neste artigo correspondem à primeira fase da pesquisa, realizada por meio da análise documental.

\section{RESULTADOS E DISCUSSÃO}

Com o levantamento de dados da plataforma digital SIGAA/Proex foi realizada a seleção dos projetos de extensão, de modo que foram identificados 33 projetos da Faculdade de Medicina, 16 projetos da Escola de Enfermagem, 13 projetos da Faculdade de Odontologia e 4 projetos da Faculdade de Nutrição. Em uma análise descritiva dos dados coletados as variáveis analisadas foram organizadas conforme demonstrado a seguir.

Na Figura 1 são apresentados os dados referentes ao público-alvo e às atividades a serem desenvolvidas nos projetos de extensão. Destaca-se que foi admitido como "público-alvo interno" a equipe de trabalho (acadêmicos, docentes ou técnicos que organizam o projeto) e como "público-alvo externo" os indivíduos aos quais as ações eram destinadas (membros da comunidade que participam de ações promovidas pelo projeto).

Figura 1. Atividades desenvolvidas pelo público-alvo interno e externo dos projetos de extensão cadastrados no SIGAA/Proex da UFAL nos anos de 2018 e 2019.

\begin{tabular}{|lr|l|lr}
\hline PROJETOS & DE & PÚBLICO-ALVO & ATIVIDADES A SEREM \\
EXTENSÃO & POR & INTERNO & DESENVOLVIDAS \\
CURSO & & & &
\end{tabular}

RC: 90188

Disponível em: https://www.nucleodoconhecimento.com.br/saude/acoes- 


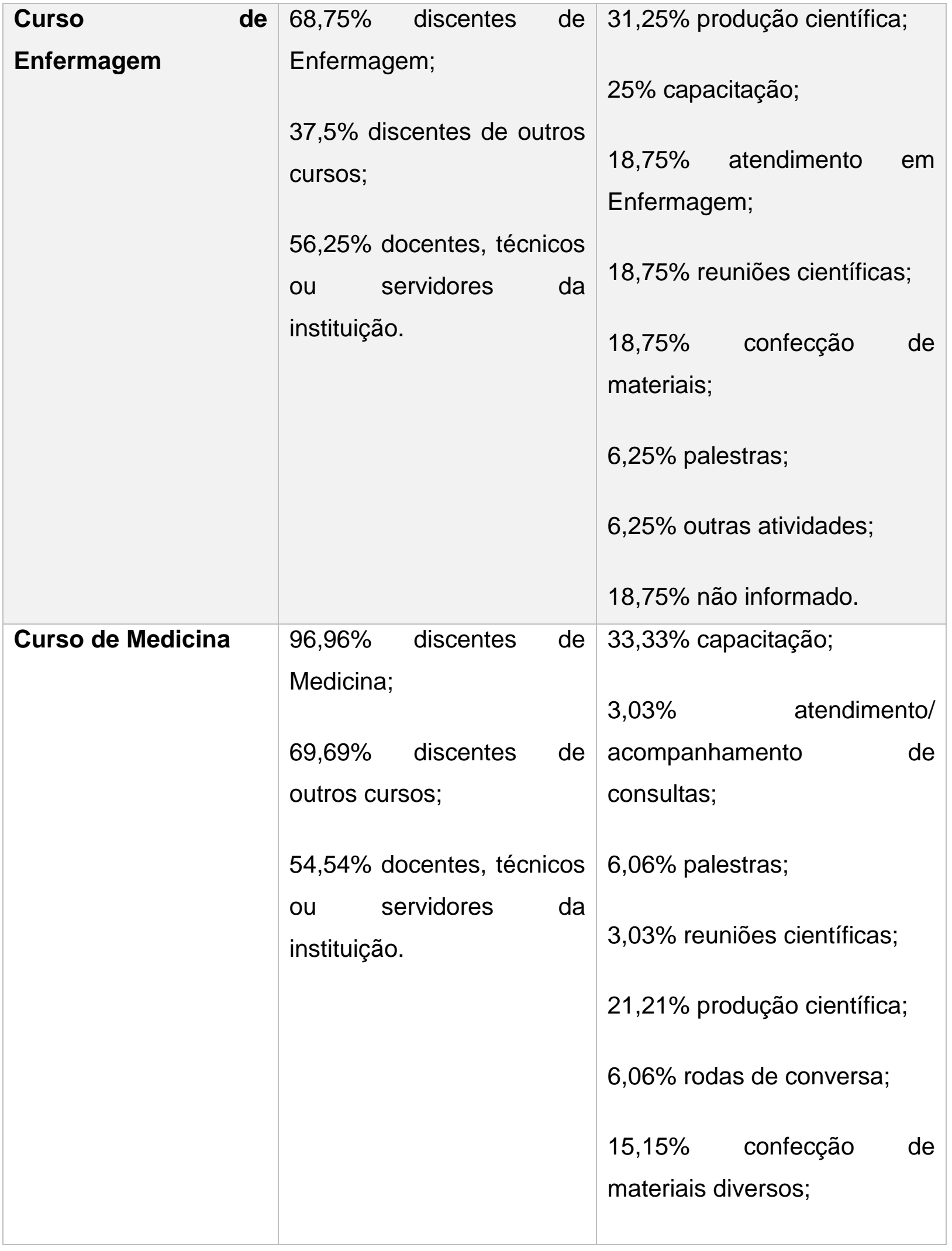

RC: 90188

Disponível em: https://www.nucleodoconhecimento.com.br/saude/acoes- 


\begin{tabular}{|c|c|c|}
\hline & & $3,03 \%$ outras atividades. \\
\hline Curso de Nutrição & $\begin{array}{l}100 \% \text { discentes de } \\
\text { Nutrição; } \\
25 \% \text { discentes de outros } \\
\text { cursos; } \\
75 \% \text { docentes, técnicos ou } \\
\text { servidores da instituição. }\end{array}$ & $\begin{array}{l}50 \% \text { capacitação; } \\
25 \% \text { reuniões científicas; } \\
50 \% \text { produção científica; } \\
50 \% \text { confecção de materiais } \\
\text { diversos; } \\
25 \% \text { outras atividades. }\end{array}$ \\
\hline $\begin{array}{l}\text { Curso } \\
\text { Odontologia }\end{array}$ & $\begin{array}{l}100 \% \text { discentes de } \\
\text { Odontologia; } \\
61,5 \% \text { docentes, técnicos } \\
\text { ou servidores da } \\
\text { instituição. }\end{array}$ & $\begin{array}{l}\text { 38,5\% produção científica; } \\
\text { 30,75\% capacitação; } \\
23 \% \quad \text { atendimento em } \\
\text { Odontologia; } \\
\text { 23\% reuniões científicas; } \\
\text { 7,7\% palestras; } \\
\text { 7,7\% outras atividades; } \\
\text { 23\% não informado. }\end{array}$ \\
\hline
\end{tabular}

\begin{tabular}{lr|l} 
PROJETOS & DE & PÚBLICO-ALVO \\
EXTENSÃO & POR & EXTERNO \\
CURSO & &
\end{tabular}
ATIVIDADES A SEREM DESENVOLVIDAS

RC: 90188

Disponível em: https://www.nucleodoconhecimento.com.br/saude/acoes- 


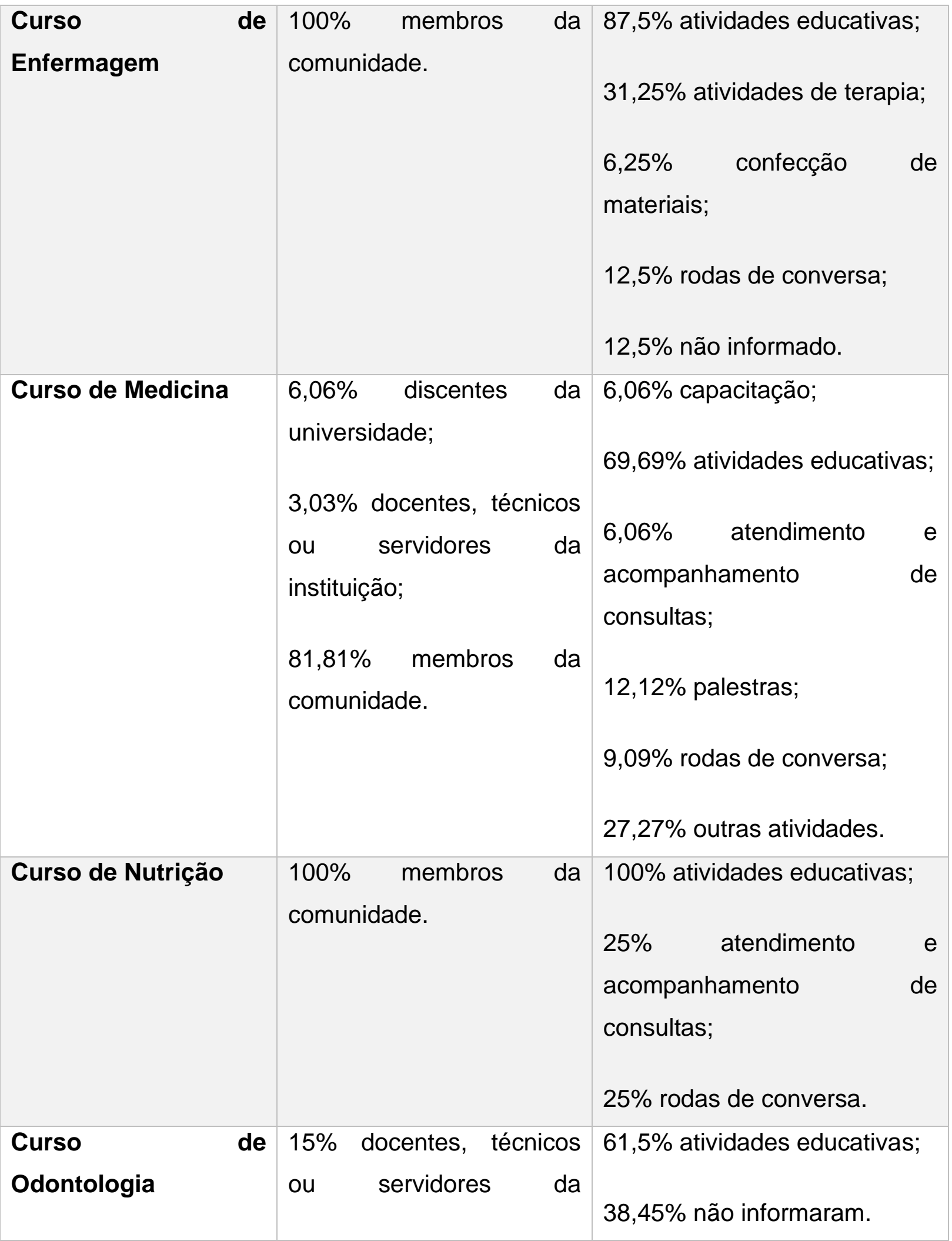

RC: 90188

Disponível em: https://www.nucleodoconhecimento.com.br/saude/acoes- 
instituição;

$92 \%$ membros da

comunidade.

Fonte: autores.

Quando se trata do público-alvo interno dos Projetos de Extensão dos cursos da área da saúde da UFAL, percebe-se que a maioria diz respeito aos próprios discentes de tais cursos. Somam-se a estes: docentes, técnicos ou servidores da própria instituição, em menor proporção. Diante desse cenário, percebe-se um impacto positivo nas relações entre professores e alunos no âmbito extensionista, uma vez que o professor está em constante interação com seus alunos na prática extensionista e desempenha um papel fundamental no processo de transmissão do conhecimento e também no desenvolvimento educacional e social do corpo discente (SOARES et al., 2019). O que pode também se constituir em um deslocamento da centralidade do saber da figura do docente para os acadêmicos, com o professor ocupando um papel mais de um orientador (CASTRO, 2004).

Este público interno, por sua vez, desenvolve diversas atividades como produção científica, reuniões científicas, atendimento e acompanhamento de consultas, rodas de conversa, palestras, capacitações e confecção de materiais. Isso representa uma tentativa de aproximação do estudante com o campo prático por meio das ações extensionistas, que pode ser considerado um aspecto positivo; contudo, a extensão universitária vai muito além disso, corroborando para que a universidade cumpra seu papel como instituição comprometida com a transformação social, que aproxima a produção e a transmissão de conhecimento (PISSAIA, 2018). Além disso, tais ações muitas vezes não possibilitam maior aproximação das comunidades por não disporem de identificação com as demandas sociais vigentes nas áreas de atuação dos projetos. Na maioria das vezes, isto ocorre para tentar legitimar na prática, a oferta de cursos de maneira pontual e a prestação de serviços como uma via de

RC: 90188

Disponível em: https://www.nucleodoconhecimento.com.br/saude/acoes- 
mão única e não atrelada à troca de experiências e saberes. Tal problema poderia ser solucionado a partir de uma pesquisa prévia a respeito do melhor ambiente para atuação do projeto, no qual suas atividades serão desenvolvidas e apresentem impacto sobre as demandas da comunidade. Observa-se assim que a indissociabilidade, na qual novas proposições que pressupõem uma ação processual e contínua, não pontual, em que o conhecimento científico interaja com os demais saberes da população, em um diálogo permanente, visando à produção de conhecimentos e a apropriação para a resolução de problemas concretos das pessoas e de suas organizações tem sido negligenciada (DE ALMEIDA, 2010).

Para uma análise do público-alvo externo resgata-se o conceito de que a prática da Extensão tem origem na concepção de universidade detentora de um saber que deve ser transferido à população e também ser colocado para assistir à mesma com o provimento de algum serviço (DE ALMEIDA, 2010). Nessa perspectiva, a extensão universitária pressupõe uma ação junto à comunidade, disponibilizando ao público externo o conhecimento adquirido com 0 ensino e a pesquisa que foram desenvolvidos pela instituição. Essa aproximação é uma maneira eficiente de trocar conhecimentos e experiências entre professores, alunos e população, pela possibilidade de desenvolvimento de processos de ensino-aprendizagem a partir de práticas cotidianas. $\mathrm{Na}$ área da saúde, as trocas de conhecimento assumem particular importância na medida em que se integram à rede assistencial e podem servir de espaço diferenciado para novas experiências voltadas à humanização, ao cuidado e à qualificação da atenção à saúde (RAUBER, 2017).

Tendo isto em vista, o público-alvo externo dos Projetos de Extensão dos cursos de saúde da UFAL apresentou-se majoritariamente composto por membros da comunidade. Assim, pode-se dizer que os projetos de extensão buscam cumprir seu papel extensionista com ações voltadas para a comunidade que vão além das salas de aula e dos laboratórios. Dessa forma, tal prática possibilita que no encontro entre alunos, professores e comunidade seja possível incorporar outros saberes e ampliar

RC: 90188

Disponível em: https://www.nucleodoconhecimento.com.br/saude/acoes- 
a capacidade de reflexão sobre diversos assuntos, por meio da troca de experiências, indo ao encontro a uma das características principais da extensão que possibilita uma mudança no processo de ensinar e aprender (FORPROEX, 2012).

Também foi possível perceber que as Atividades Educativas estão presentes na maioria dos Projetos de Extensão, o que consiste num ponto fundamental para formação dos estudantes, uma vez que já é evidenciado que acadêmicos que desenvolvem atividades extensionistas tornam-se profissionais mais responsáveis (SILVA; RIBEIRO; SILVA, 2013). Ademais, as atividades de educação em saúde, possibilitam a utilização de diferentes dinâmicas, como debates, palestras, rodas de conversa e oficinas, com o intuito de interagir com o público externo, desmistificando e construindo novas perspectivas a partir da análise crítica de fatos e mitos, conceitos e preconceitos (SENA; RABELO; ESCALANTE, 2018). Observou-se também que alguns Projetos possuem mais de um tipo de ação desenvolvida em suas propostas, o que pode ser considerado importante uma vez que a diversidade de atividades proporciona uma ampliação da possibilidade de trocas de conhecimentos e saberes (BATISTA, 2018).

Figura 2. Área do conhecimento, natureza da ação e quantidade de cursos envolvidos nos projetos de extensão cadastrados no SIGAA/proex da UFAL nos anos de 2018 e 2019.

\begin{tabular}{|c|c|c|c|}
\hline $\begin{array}{lr}\text { PROJETOS } & \text { DE } \\
\text { EXTENSÃO } & \text { POR } \\
\text { CURSO } & \end{array}$ & $\begin{array}{l}\text { ÁREA DO } \\
\text { CONHECIMENTO }\end{array}$ & NATUREZA & $\begin{array}{l}\text { CURSOS } \\
\text { ENVOLVIDOS }\end{array}$ \\
\hline $\begin{array}{l}\text { Curso de } \\
\text { Enfermagem }\end{array}$ & $\begin{array}{l}\text { 93,75\% Saúde; } \\
\text { 6,25\% Educação. }\end{array}$ & $\begin{array}{l}43,75 \% \\
\text { interdisciplinar; } \\
56,35 \% \\
\text { disciplinar. }\end{array}$ & $\begin{array}{l}56,25 \% 1 \text { curso; } \\
43,75 \% \quad 2 \text { ou } \\
\text { mais cursos. }\end{array}$ \\
\hline
\end{tabular}

RC: 90188

Disponível em: https://www.nucleodoconhecimento.com.br/saude/acoes- 


\begin{tabular}{|c|c|c|c|}
\hline Curso de Medicina & $\begin{array}{l}\text { 90,90\% Saúde; } \\
\text { 3,03\% Comunicação; } \\
\text { 3,03\% Educação; } \\
\text { 3,03\% Direitos } \\
\text { Humanos e Justiça. }\end{array}$ & $\begin{array}{l}75,75 \% \\
\text { interdisciplinar; } \\
24,25 \% \\
\text { disciplinar. }\end{array}$ & $\begin{array}{l}24 \% 1 \text { curso; } \\
61 \% 2 \text { ou mais } \\
\text { cursos; } \\
\text { 15\% não } \\
\text { informado. }\end{array}$ \\
\hline Curso de Nutrição & 100\% Saúde. & $\begin{array}{l}25 \% \\
\text { interdisciplinar; } \\
75 \% \text { disciplinar. }\end{array}$ & $\begin{array}{l}75 \% 1 \text { curso; } \\
25 \% 2 \text { ou mais } \\
\text { cursos. }\end{array}$ \\
\hline $\begin{array}{l}\text { Curso } \\
\text { Odontologia }\end{array}$ & 100\% Saúde. & $\begin{array}{l}23 \% \\
\text { interdisciplinar; } \\
77 \% \text { disciplinar. }\end{array}$ & $\begin{array}{l}69,25 \% 1 \text { curso; } \\
23 \% 2 \text { ou mais } \\
\text { cursos; } \\
7,75 \% \text { não } \\
\text { informado. }\end{array}$ \\
\hline
\end{tabular}

Fonte: autores.

A PNE pretende, a partir das áreas temáticas da Extensão Universitária, aumentar seu grau de consonância com os desafios contemporâneos e com as demandas interdisciplinares. Em vista disso, o eixo Áreas Temáticas, apresentado na PNE, tem por objetivo nortear a sistematização das ações de Extensão Universitária em oito áreas correspondentes a grandes focos de política social, sendo elas: Comunicação, Cultura, Direitos Humanos e Justiça, Educação, Meio Ambiente, Saúde, Tecnologia e Produção e Trabalho. Daí advém a importância de se analisar a Área de Conhecimento no âmbito dos Projetos de Extensão da UFAL (FORPROEX, 2012). Nesse sentido, conforme demonstrado na Figura 2, percebeu-se que o eixo "saúde" foi aquele que apresentou maior proporção quando estudados os cursos da área da

RC: 90188

Disponível em: https://www.nucleodoconhecimento.com.br/saude/acoes- 
saúde da UFAL, sendo evidenciado de forma exclusiva nos projetos dos cursos de Nutrição e Odontologia. Já os cursos de Enfermagem e Medicina apresentaram maior diversidade dentro das oito áreas correspondentes aos grandes focos de política social.

É evidente que as dificuldades conceituais e práticas no que se refere à extensão universitária e sua implementação apresentam-se como questões complexas, sendo que uma das principais dificuldades consiste na exigência de uma postura aberta à interdisciplinaridade com vistas ao diálogo (DE LEUCAS et al., 2017). Diante disso, percebeu-se que muito ainda precisa ser feito, uma vez que grande parte das ações de extensão desenvolvidas nos cursos da área da saúde da UFAL são de caráter disciplinar, excetuando-se o curso de medicina, que apresentou o caráter interdisciplinar prevalente no que diz respeito à natureza dos projetos de extensão desenvolvidos. A natureza disciplinar, neste cenário, afasta o aluno de uma visão ampla e integrada da realidade social potencializada por meio do contato com acadêmicos de diferentes cursos da área da saúde, capazes de se colocarem no contexto prático com uma postura mais crítica e ativa (FORPROEX, 2012). Nesse sentido, espera-se que o processo de formação dos profissionais da área da saúde na universidade inclua conteúdos e metodologias com enfoque na interdisciplinaridade, tornando assim mais efetivo o processo de ensino e aprendizagem. É preciso, portanto, que tais atividades sejam voltadas para as dimensões biopsicossociais, atentando para desenvolver autocrítica e autoavaliação durante o processo de formação acadêmica com enfoque na responsabilidade social como disseminadora da saúde na sociedade (BURON, 2019).

Ainda relacionado à natureza dos Projetos de Extensão, foi possível perceber que cerca de $25 \%$ dos Projetos apresentavam vínculo e envolvimento com mais de um curso, nota-se que esta proporção se apresentou coerente quando correlacionada à natureza dos Projetos analisada anteriormente. Isso indica uma dificuldade dos Projetos de extensão em estabelecer parcerias internas com outros cursos, apesar

RC: 90188

Disponível em: https://www.nucleodoconhecimento.com.br/saude/acoes- 
da inquestionável contribuição de outras áreas para trocas de saberes, produção e construção de um conhecimento ampliado (DE PAULA, 2013). Além disso, representa um déficit nas ações desenvolvidas, uma vez que a extensão se qualifica como atividade imprescindível na solução de problemas da realidade social e a interdisciplinaridade é fundamental para o desenvolvimento das atividades extensionistas de forma a valorizar os diferentes pontos de vista sobre os assuntos abordados (FUJITA, 2014).

Figura 3. Local de desenvolvimento das atividades dos projetos de extensão cadastrados no SIGAA/Proex da UFAL nos anos de 2018 e 2019.

\begin{tabular}{|l|l|}
\hline PROJETOS DE EXTENSÃO POR CURSO & LOCAL DE DESENVOLVIMENTO \\
\hline Curso de Enfermagem & $37,5 \%$ HUPPA; \\
\hline & $31,25 \%$ UFAL; \\
\hline & $18,5 \%$ comunidades de Maceió; \\
\hline & $18,5 \%$ CAPs; \\
\hline Curso de Medicina & $12,5 \%$ Escolas Públicas de Maceió; \\
\hline & $12,5 \%$ outras localidades. \\
\hline & $27,27 \%$ escolas; \\
\hline & $24,24 \%$ HUPAA; \\
\hline & $12,12 \%$ UFAL; \\
\hline & $9,09 \%$ unidade básica de saúde; \\
\hline & $6,06 \%$ comunidade; \\
\hline
\end{tabular}

RC: 90188

Disponível em: https://www.nucleodoconhecimento.com.br/saude/acoes- 
Curso de Nutrição

\section{Curso de Odontologia \\ $25,0 \%$ HUPAA. \\ $84,5 \%$ UFAL;}

$18,18 \%$ outras localidades.

$75,0 \%$ UFAL;

$15,5,7 \%$ outras localidades.

Fonte: autores.

Ao se definir a extensão universitária como um processo que promove a relação transformadora entre Universidade e outros setores da sociedade percebe-se que tal interação gera uma mudança tanto na Universidade quanto nas esferas sociais com as quais ela se relaciona (FORPROEX, 2012). Ambientes além dos muros da Universidade como ruas, praças públicas, escolas, salões de igrejas, quadras ou centros comunitários, teatros, abrigos para refugiados e desabrigados, casas de apoio e outros locais onde possa haver a tríade saúde-doença-cuidado apresentam potencial para prestação de serviços e se tornam capazes de produzir novas formas de aprendizado ao estudante da área da saúde, possibilitando ainda a disseminação de conhecimento para outros públicos permitindo uma troca mútua de saberes (AYRES, 2015). Dessa forma, as atividades extensionistas propiciam uma relação direta entre a Universidade e membros da comunidade, permitindo assim uma intervenção sobre a realidade local (LIMA, 2016). Diante disso, verifica-se a importância de executar as atividades de extensão universitária em ambientes estratégicos que promovam e facilitem a interação entre a comunidade interna e externa da Universidade a fim de que o impacto e a transformação social sejam alcançados. Cabe destacar ainda que as experiências vivenciadas fora do ambiente universitário levam à reflexão não só sobre o ensino técnico inerente à graduação, mas também sobre questões dificilmente levantadas em ambientes como a sala de aula, laboratórios, unidades de saúde e hospitais vinculados à própria universidade, levando assim o aluno a explorar e desenvolver habilidades e competências

RC: 90188

Disponível em: https://www.nucleodoconhecimento.com.br/saude/acoes- 
necessárias à sua área de atuação, como a liderança e tomada de decisões a partir de uma análise crítica de diversas situações, adaptação de linguagem em diálogos com a comunidade (BRASIL, 2014).

Nesse contexto, de acordo com a Figura 3, evidencia-se que na UFAL os projetos de extensão são desenvolvidos em sua maioria na própria universidade ou em hospital vinculado a esta. Percebe-se então que o exercício das atividades extensionistas fora do ambiente técnico-científico da universidade é uma prática ainda incipiente e que pode comprometer o objetivo de inserção do aluno na comunidade e seu aprendizado por meio de novas práticas de ensino, bem como, pode haver um comprometimento no que diz respeito à transformação social da comunidade. Cabe aqui a ressalva de que um elevado percentual - os projetos de extensão do curso de Medicina - são desenvolvidos em escolas da região. No entanto, esse número ainda é superado pela soma dos projetos desenvolvidos na própria universidade e no hospital universitário.

Realizada esta primeira análise descritiva, seguiu-se para uma análise da consonância entre Projetos de Extensão com as diretrizes da Política Nacional de Extensão (PNE). Para tanto, avaliou-se a presença das diretrizes conforme apresentado na Figura 4:

RC: 90188

Disponível em: https://www.nucleodoconhecimento.com.br/saude/acoes- 
Figura 4. Presença das diretrizes da política nacional de extensão nos projetos cadastrados no SIGAA/Proex da UFAL nos anos de 2018 e 2019.

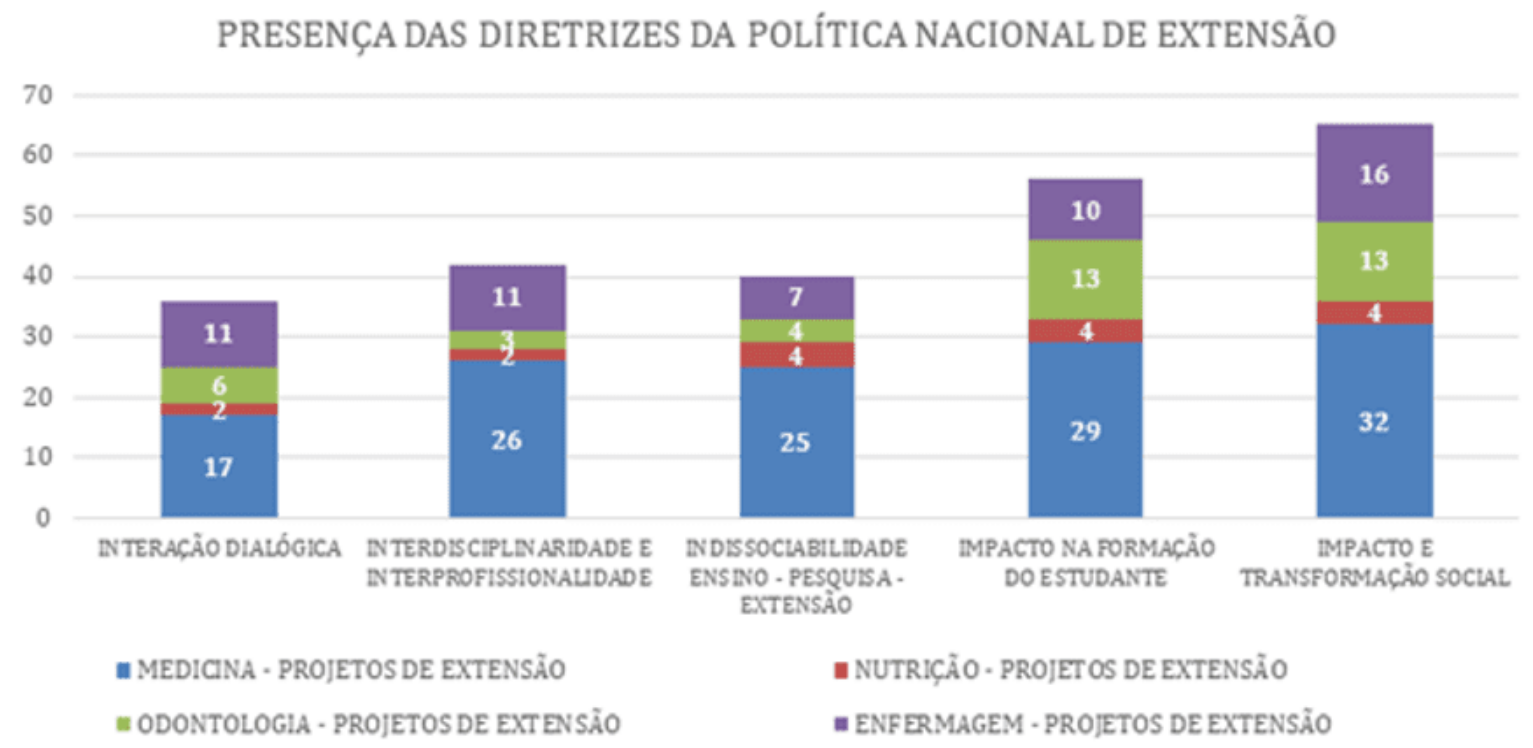

Fonte: autores.

De acordo com as propostas analisadas, pode-se avaliar a presença da diretriz de Interação Dialógica em aproximadamente metade dos projetos de extensão dos cursos de Medicina, Nutrição e Odontologia e em cerca de $70 \%$ dos projetos do curso de Enfermagem. Tal diretriz é fundamental para que haja diálogo entre membros da Universidade e comunidade e troca de saberes através da interação com a sociedade, e apesar de tamanha relevância, a interação dialógica ainda é pouco evidenciada nas ações de extensão analisadas (FORPROEX, 2012). Com o exercício da interação dialógica torna-se possível conceber um trabalho coparticipativo e compartilhado entre a universidade e a sociedade, de modo que o conhecimento compartido contribui para a superação de desigualdades e exclusão social (DE ANDRADE, 2015). Cabe aqui a ressalva de que apesar das ações de extensão indicarem a presença de interação dialógica, as propostas dos projetos em sua grande maioria não são construídas em colaboração com a comunidade, o que nos indica uma falha tanto na compreensão do conceito de interação dialógica quanto no exercício dessa diretriz.

RC: 90188

Disponível em: https://www.nucleodoconhecimento.com.br/saude/acoes- 
Com relação à diretriz de Interdisciplinaridade e Interprofissionalidade deve-se esclarecer que há uma dificuldade em avaliar a presença de interprofissionalidade nas ações de extensão, que não é posta tão em evidência quanto a interdisciplinaridade e chega a ser tratada como um conceito único e semelhante a interdisciplinaridade; uma vez que a Política Nacional de Extensão trata dos dois conceitos como uma única diretriz, optou-se por manter ambos em um mesmo quesito de análise. A presença dessa diretriz foi demonstrada na maior parte dos projetos de extensão dos cursos de Medicina e Enfermagem e em menor proporção nos projetos de extensão do curso de Nutrição e Odontologia. Sabe-se que a importância da prática da interdisciplinaridade e também da interação com outros setores sociais reside no fato de que estas levam à interprofissionalidade e interinstitucionalidade, promovendo ainda 0 aprimoramento de relações interpessoais (CORRÊA, 2003). A interdisciplinaridade e a interprofissionalidade, unidas, buscam a superação da estrutura fragmentada das instituições de ensino superior e seu currículos acadêmicos. Sabe-se que a concepção uniprofissional não é capaz de formar profissionais hábeis a atuar frente às adversidades da sociedade, tendo em vista a natureza heterogênea dos acontecimentos e necessidades de saúde (RIOS; SOUZA; CAPUTO, 2019). Nota-se então que se faz necessário um grande avanço na conversão das ações extensionistas da UFAL em atividades interdisciplinares, ainda muito carentes do conceito e aplicação prática tanto da interdisciplinaridade quanto da interprofissionalidade.

No que diz respeito à diretriz de Indissociabilidade Ensino-Pesquisa-Extensão, Gonçalves afirma que:

O princípio da indissociabilidade entre Ensino, Pesquisa e Extensão pode ser compreendido como uma resposta a demandas sociais por uma Universidade socialmente responsável, que dialogue mais ativamente com diversos setores da sociedade e que propugne uma formação e produção de conhecimento em diálogo com necessidades sociais (GONÇALVES, 2015, p. 1235).

RC: 90188

Disponível em: https://www.nucleodoconhecimento.com.br/saude/acoes- 
Nesse contexto, sabe-se que as ações de extensão se tornam mais efetivas quando associadas ao processo de formação de pessoas (Ensino) e de geração de conhecimento (Pesquisa), sendo esta diretriz a representação de um tripé fundamental para o bom funcionamento das ações extensionistas e desenvolvimento da capacidade de alcançar seus objetivos de atuação (NOGUEIRA, 2000). Esta aparenta ser uma diretriz mais valorizada pelos cursos de Medicina e Nutrição, que a evidenciam em quase todos os seus projetos de extensão. Já os cursos de Enfermagem e Odontologia deixam menos explícito em suas propostas a presença de indissociabilidade ensino-pesquisa-extensão, uma vez que menos da metade das atividades extensionistas desses cursos apresentam tal diretriz em suas propostas.

É sabido que há uma crescente preocupação com o perfil do profissional de saúde, que cada vez mais precisa desenvolver habilidades que o tornem capaz de atuar na sociedade dentro de uma contexto de grandes transformações, não somente de sua própria área de atuação profissional, mas também nas esferas política e social (COSTA, 2007). Nesse contexto, surge a diretriz de Impacto na Formação do Estudante, que é posta em evidência na grande maioria das propostas de ações analisadas. Tal diretriz reside na busca por uma formação mais consciente de seu papel no mundo e de pensamento crítico, político, histórico e humano; nota-se que quase em sua totalidade os projetos buscam ser diretamente relevantes para a formação do estudante (KOCHHANN et al., 2016).

E, por fim, a análise das propostas demonstrou que a diretriz de Impacto e Transformação social pode ser plenamente verificada nas propostas dos projetos de extensão dos cursos de saúde da universidade. Ao se entender a extensão universitária como um trabalho, pressupõe-se que as atividades por ela praticadas sejam ações deliberadas capazes de criar dois produtos principais: o conhecimento e a transformação social (DE MELO, 2003); nesse contexto a extensão universitária atua como instrumento de mudança social e da própria universidade; com os dados encontrados nesta pesquisa verifica-se que aproximadamente $100 \%$ das ações de

RC: 90188

Disponível em: https://www.nucleodoconhecimento.com.br/saude/acoesextensionistas 
extensão analisadas tem conhecimento do compromisso de transformação social da extensão e atuam em prol de um verdadeiro impacto de suas ações na sociedade (GADOTTI, 2017).

Nota-se dessa forma que as diretrizes preconizadas pela Política Nacional de Extensão, de uma forma geral podem ser bem evidenciadas nos projetos de extensão.

\section{CONSIDERAÇÕES FINAIS}

A extensão universitária é uma atividade essencial no contexto atual do país para aproximação dos acadêmicos dos cursos da área da saúde com o campo prático, mas, muito além disso, trata-se de um instrumento capaz de proporcionar diferentes cenários de ensino e aprendizagem embasados na troca de saberes entre docentes, discentes e comunidade com vistas às necessidades sociais em saúde.

No contexto da universidade abordada, observou-se que as atividades educativas foram as principais ações desenvolvidas pelos projetos possibilitando 0 desenvolvimento de debates, palestras, rodas de conversa e oficinas, com o intuito de interagir com o público externo. Já quando se trata do processo de formação dos profissionais da área da saúde na universidade foi possível perceber que conteúdos e metodologias com enfoque na interdisciplinaridade ainda carecem de aperfeiçoamento para tornar o processo de ensino e aprendizagem mais efetivo. Nota-se que há uma necessidade de maior inserção das atividades extensionistas no ambiente das comunidades, fora da universidade; e, aliado a isso, percebe-se que há um déficit no enquadramento e prática de algumas diretrizes preconizadas pela PNE, em destaque a diretriz de Interação Dialógica, ainda tão pouco compreendida quanto executada.

Deve-se considerar que com a instituição da curricularização da Extensão Universitária as atividades extensionistas passam por um momento importante para

RC: 90188

Disponível em: https://www.nucleodoconhecimento.com.br/saude/acoes- 
sua consolidação como fazer acadêmico. Contudo, se faz necessária ainda a criação de novas técnicas e estratégias que permitam uma articulação entre a universidade e comunidade de forma mais eficiente. Este é um desafio importante e que deve ser superado para que as diretrizes propostas pela Política Nacional de Extensão sejam cumpridas e que a Extensão Universitária seja integralizada nas universidades brasileiras a fim de cumprir seu papel como ferramenta capaz de proporcionar uma troca de saberes entre universidade e comunidade.

\section{REFERÊNCIAS}

ABDALLA, I. G. et al. Projeto pedagógico e as mudanças na educação médica. Rev bras educ méd, v. 33, n. Supl 1, p. 44-52, 2009.

BATISTA, Z. N.; KERBAUY, M. T. M. A gênese da Extensão Universitária brasileira no contexto de formação do Ensino Superior. Revista Ibero-Americana de Estudos em Educação, v. 13, n. 3, p. 916-930, 2018.

BRASIL. Constituição Federal de 1988. Promulgada em 5 de outubro de 1988.

BRASIL. Lei №13.005, de 25 de junho de 2014. Aprova o Plano Nacional de Educação - PNE e dá outras providências. Presidência da República, Casa Civil, Subchefia para Assuntos Jurídicos. BRASIL.

Resolução CNE/CES №3, de 19 de fevereiro de 2002. Institui Diretrizes Curriculares Nacionais do Curso de Graduação em Odontologia. Diário Oficial da União, Brasília, 4 de março de 2002.

BRASIL. Resolução CNE/CES №3, de 7 de novembro de 2001. Institui Diretrizes Curriculares Nacionais do Curso de Graduação em Enfermagem. Diário Oficial da União, Brasília, 9 de Novembro de 2001.

RC: 90188

Disponível em: https://www.nucleodoconhecimento.com.br/saude/acoes- 
BRASIL. Resolução CNE/CES №5, de 7 de novembro de 2001. Institui Diretrizes Curriculares Nacionais do Curso de Graduação em Nutrição. Diário Oficial da União, Brasília, 9 de Novembro de 2001.

BRASIL. Resolução №7, de 18 de dezembro de 2018. Conselho Nacional de Educação. Câmara de Educação Superior. Estabelece as Diretrizes para a Extensão na Educação Superior Brasileira e regimenta o disposto na Meta 12.7 da Lei no13.005/2014, que aprova o Plano Nacional de Educação - PNE 2014-2024 e dá outras providências.

BRASIL. Resolução №3, de 20 de junho de 2014. Institui Diretrizes Curriculares Nacionais do Curso de Graduação em Medicina e dá outras providências. Diário Oficial da União. Brasília, DF, 23 de junho de 2014.

BRASIL. Resolução №3, de 7 de novembro de 2001. Institui Diretrizes Curriculares Nacionais do Curso de Graduação em Enfermagem. Diário Oficial da União. 2001; Seção 1, p. 37.

BURON, R. M. O perfil profissional na área da saúde Um olhar a partir da universidade e do mercado de trabalho. 2019.

CASTRO, L. M. C. A universidade, a extensão universitária e a produção de conhecimentos emancipadores. Reunião anual da ANPED, v. 27, p. 1-16, 2004.

CAVALCANTE, A. S. P. et al. As ligas acadêmicas na área da saúde: lacunas do conhecimento na produção científica brasileira. Revista Brasileira de Educação Médica, v. 42, n. 1, p. 199-206, 2018.

COSTA, N. M. S. C. Docência no ensino médico: por que é tão difícil mudar? Rev. Bras. Educ. Med., v. 31, n. 1, p. 21-30, 2007.

RC: 90188

Disponível em: https://www.nucleodoconhecimento.com.br/saude/acoes- 
CORRÊA, E. J. Extensão universitária, política institucional e inclusão social. Revista Brasileira de extensão universitária, v. 1, n. 1, p. 12-15, 2003.

DE ALMEIDA, A. S. A contribuição da extensão universitária para o desenvolvimento de Tecnologias Sociais. 2010.

DE ANDRADE, R. M. M.; WIEBUSCH, E. M. A Extensão Universitária na perspectiva da interação dialógica. 2015.

DE CARVALHO, C. R. et al. Contribuição das Ligas Acadêmicas para Formação em Enfermagem. Enfermagem em Foco, v. 10, n. 6, 2019.

AYRES, J. R. M. C. Extensão universitária: aprender fazendo, fazer aprendendo. Revista de Medicina, v. 94, n. 2, p. 75-80, 2015.

DE LEUCAS, C. B.; DE OLIVEIRA, L.; DE ALMEIDA, T. F. S. Extensão Universitária: Formação Transdisciplinar na Graduação. In: IV CONGRESSO NACIONAL DE EDUCAÇÃO CATÓLICA. 2017, p. 33.

DE MELO NETO, J. F. Extensão universitária e produção do conhecimento. 2003.

DE PAULA, J. A. A extensão universitária: história, conceito e propostas. InterfacesRevista de Extensão da UFMG, v. 1, n. 1, p. 5-23, 2013.

FORPROEX. Política Nacional de Extensão Universitária. Manaus: FORPROEX, 2012.

FUJITA, M. S. L.; BARRAVIERA, B. Revista Ciência em Extensão: 10 anos disseminando conhecimento e transformando a relação entre a Universidade e a Sociedade. Revista Ciência em Extensão, v. 10, n. 3, p. 2-4, 2014.

GADOTTI, M. Extensão universitária: para quê. São Paulo: Instituto Paulo Freire, 2017.

RC: 90188

Disponível em: https://www.nucleodoconhecimento.com.br/saude/acoes- 
GONÇALVES, N. G. Indissociabilidade entre Ensino, Pesquisa e Extensão: um princípio necessário. Perspectiva, v. 33, n. 3, p. 1229-1256, 2015.

KOCHHANN, A. M.; SILVA, KACPC. A formação de professores no curso de pedagogia: perspectivas e limites da extensão universitária. Anais da V Semana de Integração. Inhumas: UEG, p. 286-296, 2016.

LIMA, J. R. O. et al. A prática da extensão universitária como incentivadora da tecnologia social. Revista Brasileira de Tecnologias Sociais, v. 3, n. 1, p. 93-100, 2016.

NOGUEIRA, M. D. P. (org) Extensão Universitária: diretrizes conceituais e políticas: Documentos Básicos do Fórum Nacional de Pró-Reitores de Extensão das Universidades Públicas Brasileiras. Belo Horizonte: PROEX/UFMG; Fórum, 2000.

PISSAIA, L. F. et al. Relato de experiência: qualificação da extensão universitária na área da saúde por meio de estratégias de ensino contemporâneas. Research, Society and Development, v. 7, n. 2, p. 3, 2018.

RAUBER, S. B. Extensão universitária e formação profissional: Indissociáveis no processo de aprendizagem da Universidade Católica de Brasília (UCB). 2017.

RIOS, D. R. S.; SOUSA, D. A. B.; CAPUTO, M. C. Diálogos interprofissionais e interdisciplinares na prática extensionista: o caminho para a inserção do conceito ampliado de saúde na formação acadêmica. Interface-Comunicação, Saúde, Educação, v. 23, 2019.

SILVA, A. F. L.; RIBEIRO, C. D. M.; SILVA, A. G. Pensando extensão universitária como campo de formação em saúde: uma experiência na Universidade Federal Fluminense, Brasil. Revista Interface-Comunicação Saúde Educação, Niterói, v. 17, n. 45, p. 371-384, abr./jun. 2013.

RC: 90188

Disponível em: https://www.nucleodoconhecimento.com.br/saude/acoesextensionistas 
SENA, K. G.; RABELO, L. G.; ESCALANTE, R. D. Metodologias ativas de ensino e o impacto inovador na graduação. Revista EDaPECI, v. 18, n. 3, p. 71-79, 2018.

SOARES, J. F. S. et al. As Habilidades Sociais como Fatores Aliados às Práticas do Professor. Revista da Universidade Vale do Rio Verde, v. 17, n. 1, 2019.

Enviado: Março, 2021.

Aprovado: Julho, 2021.

RC: 90188

Disponível em: https://www.nucleodoconhecimento.com.br/saude/acoesextensionistas 